\title{
Development of a Demountable Fire Test Corridor for Assessment of Floor Coverings
}

\author{
NEVILLE A. McARTHUR and COLIN B. JOLLIFFE \\ CSIRO Division of Building, Construction and Engineering \\ PO Box 56, Highett, Victoria 3190, Australia
}

\begin{abstract}
Presently in Australia there exists an industry-expressed need for a large-scale fire test method to be developed for floor coverings, in order that the validity of AS 1530 Part 3 [1], the method currently specified for control of floor coverings, can be assessed and, if necessary, a replacement test method can be validated. This paper describes the development of a fire test room and $10 \mathrm{~m}$ demountable corridor facility to meet this need. It discusses experiments in which heat release rate and flame spread distance were measured as a function of time for wool, nylon and polypropylene carpets burnt in the corridor.
\end{abstract}

Keywords: Large-scale fire tests, corridor tests, carpets, flame spread, flashover, heat release rate, total heat release.

\section{INTRODUCTION}

Presently the Building Code of Australia (BCA) [2] requires carpet proposed for use in all buildings except detached dwellings to be tested to Australian Standard 1530 Part 3. There is no equivalent overseas test method and there are few correlations with existing overseas tests.

The basis of the test method is a vertically mounted gas-fired radiant panel towards which a vertically mounted $600 \times 450 \mathrm{~mm}$ specimen is moved. Decomposition products are subjected to piloted ignition from a fixed or an operator-controlled gas pilot flame. Once the specimen ignites, movement towards the radiant panel is stopped and measurements of heat release, smoke release and 'spread of flame' are made. Spread of flame is measured indirectly, by measuring the time after ignition for radiation emitted by the specimen to increase by $1.4 \mathrm{~kW} / \mathrm{m}^{2}$. These results are processed into indices designated Ignitability Index, Spread of Flame Index, Heat Developed Index and Smoke Developed Index. Whilst the Standard requires actual results to be reported, it allows assignment of indices for regulatory purposes. In fact, regulators only call up the Spread of Flame Index and the Smoke Developed Index. 
When carpets with thermoplastic pile are examined on the AS 1530 Part 3 test, the vertical specimen orientation often causes the pile to move downwards as it melts under heating from the radiant panel. This effect can be exacerbated if the carpet also has a thermoplastic backing. This behaviour can lead to considerably lower Spread of Flame Indices than would be the case if the material remained in place. A further difficulty with the method is that the burning behaviour of a carpet which is difficult to ignite will be examined at a higher applied radiation load than will that of a carpet that ignites rapidly. Thus, a carpet with superior fire performance in large-scale tests may get poorer results from this test than a carpet with inferior fire performance.

An alternative small-scale fire test method, proposed some years ago as a replacement for AS 1530 Part 3 for carpets is the 'Flooring Radiant Panel' test (ASTM E648) [3]. It represents a scenario where a well-developed fire (e.g. a room fire at flashover) is radiating on to a floor covering. This method exposes a horizontal carpet specimen to an inclined radiant panel representing the fire and to a pilot flame. Flame propagation along the carpet is measured. If it ceases, the radiant heat level falling on the carpet at the point where this occurs is designated the 'critical radiant flux' (CRF) for flame propagation. Values for CRF generally range from 1 to $8 \mathrm{~kW} / \mathrm{m}^{2}$, with higher values representing better performance. This test was issued some years ago as a draft Australian Standard. The fact that it did not include measurement of smoke release was a factor in the non-adoption of this test as a replacement for AS 1530 Part 3.

Another test method which may prove to be appropriate for floor coverings is the cone calorimeter [4,5], however experience with this test with floor coverings is limited.

It will take some years for research results to appear as recommendations to be considered by the Australian Building Codes Board and, if accepted, be included in amendments for adoption by the various States and Territories. In the meantime, the industry expressed a need for carpet systems to be assessed for particular applications where current requirements precluded their use. Full-scale comparative testing of a candidate floor covering system against a 'benchmark' system which complied with the requirements of BCA Specification $\mathrm{C} 1.10$ would give results which could form the basis of a fire engineering assessment of the candidate system and the particular building (and fire safety system) in which it was proposed for use. Such full-scale comparative testing could be carried out in a suitable fire test room and corridor facility.

\section{FIRE TEST ROOM AND CORRIDOR}

\section{Background}

A literature search revealed several references to the fire performance of floor coverings being investigated in a large-scale corridor facility. Fung et al. [6] used a $9.2 \times 2.4 \times 2.4 \mathrm{~m}$ corridor at the National Bureau of Standards to investigate the fire behaviour of a number of floor covering materials. Their principal findings were:

(a) the primary hazard was rapid flame spread from the burn room down the length of the corridor;

(b) most of the energy released in the room was transferred into the corridor by radiation and convection; and

(c) radiant preheating of the floor covering prior to rapid flame spread was the dominant mode of heat transfer. 
All but one of the nine experiments they conducted on acrylic, nylon and wool carpets resulted in flames propagating down the whole length of the corridor. Maximum rates of heat release of over $6 \mathrm{MW}$ were obtained.

Quintiere and Huggett [7] analysed these and succeeding experiments in great detail, to identify the nature of the potential flame spread hazard of flooring materials. They examined a number of small-scale fire spread test methods for floor covering materials and compared their results with those from the corridor. They recommended a radiant panel test as the small-scale fire test for flooring materials.

Quintiere [8] analysed data from four of these experiments to examine the factors influencing fire propagation. He concluded that flashover depends on the interaction of the burning material and its surroundings. A fire test method measures a fire 'property' or characteristic of the material while burning in a particular environment. Correlation of flashover with fire test method results can be questionable unless both the test method and fire experiment are well understood. Even with this understanding, correlation of flashover with a relevant fire test method may prove to be insufficient since additional parameters related to the material and its environment may be important.

The work carried out by Christian and Waterman [9] in the SPI IITRI $16.8 \mathrm{~m}$ corridor $(1.83 \mathrm{~m}$ wide by $2.44 \mathrm{~m}$ high) investigated the performance of wall and ceiling linings only, but it gave a useful range of heat release values that could be generated in the connected fire room. Work by McGuire [10] involved a corridor of the same width and height, but it was slightly longer $(19.5 \mathrm{~m})$. Experiments were also carried out on a near quarter-scale model corridor, $4.9 \mathrm{~m}$ long and $0.61 \mathrm{~m}$ high and wide. Floor coverings, and wall and ceiling linings were examined in both corridors. Comparisons between full- and quarter-scale results revealed a marked scale effect, in that floor coverings had significantly more effect in propagating fire in the quarterscale corridor than in the full-scale corridor.

\section{Configuration}

To ensure that such a scale effect would not interfere with fire engineering calculations on results from the proposed CSIRO fire test corridor, it was decided to build the corridor to the smallest cross-sectional dimensions allowable under the BCA ( $1 \mathrm{~m}$ wide by $2.1 \mathrm{~m}$ high). This would ensure that test results could be viewed as 'worst plausible case' and that extrapolations to corridors of larger dimensions would be conservative. Whereas Christian and Waterman estimated fire source heat release rates from calorific values of the fuel load, the CSIRO corridor was to terminate in an exhaust hood matching the requirements of ISO 9705 [11], including oxygen consumption calorimetry instrumentation.

The dimensions of the connected fire room $(3.55 \times 2.35 \times 2.35 \mathrm{~m}$ high) were chosen to match the other ASTM and ISO fire test rooms in the laboratory. The whole room and corridor facility was to be constructed inside the existing laboratory building to eliminate effects of weather. Given its finite life in regards to its primary role, and due to demands on laboratory space, the facility was configured to have a fixed fire room joined to a corridor of unique modular construction, which would allow for it to be removed from the laboratory when not in use.

\section{Design and Materials}

The layout of the fire test room and corridor is shown in Figure 1. The fire room was based on a galvanised steel frame erected on a concrete slab and clad on the inside walls and ceiling with 


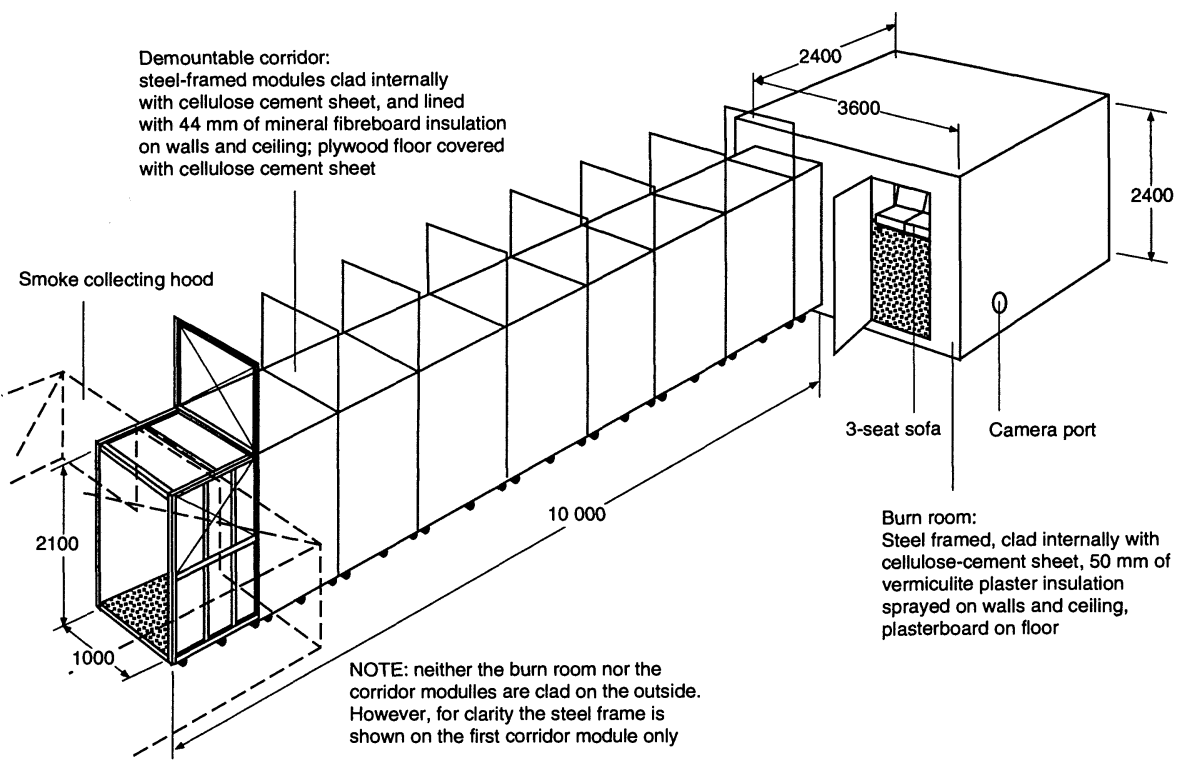

\section{FIGURE 1. Fire room and $10 \mathrm{~m}$ corridor}

$4.5 \mathrm{~mm}$ cellulose-cement sheet of mass $6.3 \mathrm{~kg} / \mathrm{m}^{2}$. The inner face of this lining was sprayed with $50 \mathrm{~mm}$ of vermiculite plaster insulation, sufficient to provide a two-hour fire resistance rating. The concrete floor was protected by a layer of $16 \mathrm{~mm}$ fibreglass-reinforced paper-faced gypsum plasterboard. On one long side of the room was a service door $0.8 \times 2.1 \mathrm{~m}$ high, and a $1.0 \times 2.1 \mathrm{~m}$ high opening into the corridor. The corridor was attached at $90^{\circ}$ to one of the long sides of the fire room, one wall of the corridor being $250 \mathrm{~mm}$ towards the centre of the long side from the adjacent short side. The walls were fitted with two ports to allow extinguishment with fire hoses in an emergency, and a floor-level camera port.

The corridor was made up of eight modules, each $1.2 \mathrm{~m}$ long, framed in galvanised steel. They were clad on the inside walls and ceiling with $4.5 \mathrm{~mm}$ cellulose-cement sheet, and on the floor with $13 \mathrm{~mm}$ five-ply plywood covered with $6 \mathrm{~mm}$ cellulose-cement. The plywood braced the modules around the vertical axis. Bracing around one horizontal axis was provided by diagonal galvanised iron straps on the side walls. Rigidity around the other horizontal axis was gained by extending one end frame of each module a further metre above the roof and adding diagonal galvanised iron braces.

The corridor was lined on the walls and ceiling with $44 \mathrm{~mm}$ of ceramic fibreboard made up of two outer $12 \mathrm{~mm}$ layers and an inner layer $20 \mathrm{~mm}$ thick. The ceramic fibreboard had a bulk density of $250 \mathrm{~kg} / \mathrm{m}^{3}$ and a thermal conductivity of $0.155 \mathrm{~W} / \mathrm{mK}$ at $600^{\circ} \mathrm{C}$.

The far end of the corridor ran $1 \mathrm{~m}$ in to a $3 \times 3 \mathrm{~m}$ square smoke collection hood. The bottom sides of this hood were $1.4 \mathrm{~m}$ above ground level. The hood was connected to an instrumented exhaust duct with a maximum capacity of $3.5 \mathrm{~m}^{3} / \mathrm{s}$ at ambient conditions. 


\section{EXPERIMENTAL PROGRAM}

In order to determine if the facility gave useful results, three carpets with different construction and different predicted large-scale fire behaviour were selected for use in development tests. These are described below. A contract carpet with $100 \%$ wool pile was selected as the benchmark carpet against which the others would be compared. When tested to AS 1530 Part 3 this carpet obtained results that complied with the requirements of BCA Specification C1.10. Tests would initially be carried out on this carpet, varying the fuel load until the carpet burned for some distance along the corridor, but did not sustain burning for the whole length of the corridor. This would give scope for the other carpets to demonstrate performance that was better, equivalent to or worse than the benchmark carpet.

\section{Specimens}

The specimen details are shown in Table 1.

\section{TABLE 1. Specimen details}

\begin{tabular}{llll}
\hline $\begin{array}{l}\text { Pile } \\
\text { Construction }\end{array}$ & $\begin{array}{l}100 \% \text { wool } \\
\text { loop pile tufted }\end{array}$ & $\begin{array}{l}100 \% \text { nylon } \\
\text { electrostatically } \\
\text { flocked }\end{array}$ & $\begin{array}{l}100 \% \text { polypropylene } \\
\text { loop pile tufted }\end{array}$ \\
Backing - primary & woven polypropylene & $\begin{array}{l}\text { glass-fibre } \\
\text { reinforced PVC } \\
\text { nil }\end{array}$ & $\begin{array}{l}\text { woven } \\
\text { polypropylene } \\
\text { jute }\end{array}$ \\
- secondary & jute & $2.10 \mathrm{~kg} / \mathrm{m}^{2}$ & $0.81 \mathrm{~kg} / \mathrm{m}^{2}$ \\
Nominal pile mass & $1.36 \mathrm{~kg} / \mathrm{m}^{2}$ & 16 & 16 \\
AS 1530 Part 3 indices* & & 7 & 8 \\
- Ignitability (range 0-20) & 15 & 5 & 6 \\
- Spread of flame (0-10) & 0 & 6 & 5 \\
- Heat evolved (0-10) & 0 & & $\dagger$ \\
- Smoke developed (0-10) & 3 & $7.6 \mathrm{~kW} / \mathrm{m}^{2}$ & $\dagger$ \\
ASTM E648 results & & & \\
- Critical radiant flux & $7.5 \mathrm{~kW} / \mathrm{m}^{2}$ & & \\
\hline
\end{tabular}

* A lower index indicates better fire performance.

$\dagger$ Results not available for this carpet. Typical result for a polypropylene carpet of this construction is 2 or less.

Carpet specimens were glued to cellulose-cement sheets by commercial carpet layers using water-based acrylic adhesive. The cellulose-cement sheets were $4.5 \mathrm{~mm}$ thick with a mass of $6.3 \mathrm{~kg} / \mathrm{m}^{2}$, cut to sizes suited to laying in the fire room and corridor. The specimens were conditioned at $23^{\circ} \mathrm{C}$ and $55 \% \mathrm{RH}$ for at least seven days prior to testing. Two experiments each were carried out for the nylon and polypropylene-pile carpets and three for the wool-pile carpet.

\section{Fuel Load}

After preliminary tests, a fuel load consisting of a three-seat mock-up sofa and a fire room floor covering of the carpet under test was selected as appropriate. This fuel load had a peak 
heat release rate of $2.5 \mathrm{MW}$, about midway between the values for 'high intensity' and 'low intensity' room fires in the work carried out by Christian and Waterman [9]. Measurements of the mass of residue from wool carpet burnt in the room allowed the estimation of the total room fuel load; $5.5 \mathrm{~kg}$ polyurethane foam, $8 \mathrm{~kg}$ carpet. This equates to $1.7 \mathrm{~kg} / \mathrm{m}^{2}$ of burn room floor area, considerably less than the $13 \mathrm{~kg} / \mathrm{m}^{2}$ load used in the NBS corridor burns, but still sufficient given the smaller corridor cross-section to promote flame propagation over the length of the corridor for some flooring materials.

The sofa, which matched that defined in Nordtest Standard NT Fire 023 [12], had a rectangular hollow-section steel frame and six cushions $560 \times 560 \times 100 \mathrm{~mm}$, made from polyurethane foam (without fire-retardant additives), designated N23-130 under the classifications given in AS 2281-1993 [13]. The cushions and carpet were conditioned for at least seven days at $23^{\circ} \mathrm{C}$ and $55 \%$ RH immediately prior to use.

\section{Instrumentation}

Temperatures in the room and corridor were measured using $0.5 \mathrm{~mm}$ shielded type $\mathrm{K}$ thermocouples. Two thermocouples were mounted $100 \mathrm{~mm}$ below the burn room ceiling adjacent to the service door. A further three were mounted $100 \mathrm{~mm}$ below the centre of the corridor ceiling at 0,5 and $10 \mathrm{~m}$ from the burn room. Twenty-one thermocouples were mounted $100 \mathrm{~mm}$ above the corridor floor, $200 \mathrm{~mm}$ in from one side, at $500 \mathrm{~mm}$ intervals along the length of the corridor. This enabled measurement of the progress of flame travel along the corridor. Heat release was measured by oxygen consumption calorimetry instrumentation mounted in the exhaust duct leading from the smoke collection hood. The hood, duct and instrumentation met the specifications given in Nordtest Standard NT Fire 032 [12].

\section{Visual Records}

Fire growth in the fire room was recorded using a video camera viewing the sofa through a floor-level toughened glass camera port. Flame spread behaviour in the corridor was recorded by a video camera mounted $5 \mathrm{~m}$ clear of the open end of the corridor. Still photographs $(35 \mathrm{~mm}$ colour prints) were taken before, after and at appropriate intervals during each experiment.

\section{PROCEDURE}

\section{Setting Up}

The specimens were removed from the conditioning room and screwed to the floor of the fire test room and corridor, immediately prior to testing. The sofa frame was loaded with cushions and was placed along the long wall of the room opposite the corridor opening, leaving $50 \mathrm{~mm}$ clearance between the sofa and the walls behind and beside it.

The sofa was ignited by applying a lighted match to the centre point of the rear top edge of the central seat cushion, igniting both the central seat and back cushions simultaneously. The service door was then closed and sealed. 


\section{Measurements and Observations}

Temperatures, heat release and smoke release were measured using instrumentation described above. The presence of flames at thermocouples along the length of the corridor was logged as the attainment of $600^{\circ} \mathrm{C}$.

After burning had ceased, the distance burnt along the carpet in the corridor (being to the furthest extent of char on the pile) was measured, and the burn pattern on the carpet was photographed. The time for the temperature $100 \mathrm{~mm}$ beneath the fire room ceiling to reach $600^{\circ} \mathrm{C}$ was taken as the time for the fire room to reach flashover. The time to burnout (the time from ignition until flame height at the furthest extent of flame travel in the corridor dropped below $100 \mathrm{~mm}$ ) was determined from the corridor video record.

\section{RESULTS AND DISCUSSION}

\section{Room Fire Growth}

In all experiments, the sofa rapidly became involved in combustion, with molten material falling on, and involving, the underlying carpet after $90( \pm 5)$ seconds. The temperature $100 \mathrm{~mm}$ below the burn room ceiling indicated that flashover conditions $\left(600^{\circ} \mathrm{C}\right)$ were reached at 110 $(+15,-20)$ seconds from ignition of the sofa. The fire spread to involve the carpet adjacent to the camera port within $120(+15,-10)$ seconds. Repeatability of the build-up of fire in the fire room thus appeared to be good.

From this stage, the carpets burned to different distances along the corridor with varying rates of heat release according to the properties of the different carpets. These results are summarised in Table 2 and are discussed below for each carpet in turn. Experiment 7 indicates that the time to flashover with the sofa alone was similar to that of the experiments involving carpets, but the heat release was considerably less, due to the lack of involvement of carpets in the burn room and corridor.

TABLE 2. Results of corridor tests

\begin{tabular}{clcccc}
\hline $\begin{array}{c}\text { Experiment } \\
\text { number }\end{array}$ & Carpet type & $\begin{array}{c}\text { Time to room } \\
\text { flashover } \\
(\mathrm{s})\end{array}$ & $\begin{array}{c}\text { Distance } \\
\text { burnt } \\
(\mathrm{m})\end{array}$ & $\begin{array}{c}\text { Time to } \\
\text { burnout } \\
(\mathrm{min}: \mathrm{s})\end{array}$ & $\begin{array}{c}\text { Total heat } \\
\text { release } \\
(\mathrm{MJ})\end{array}$ \\
\hline 2 & Wool & 110 & 5.4 & $4: 35$ & 342 \\
8 & & 120 & 3.0 & $3: 00$ & 189 \\
11 & & 125 & 7.0 & $4: 55$ & 354 \\
4 & Nylon & 105 & 2.6 & $4: 00$ & 285 \\
12 & & 115 & 3.4 & $4: 30$ & 319 \\
15 & Polypropylene & 100 & 10.0 & $6: 00$ & 419 \\
18 & & 90 & 10.0 & $5: 40$ & 409 \\
7 & Blank (sofa only) & 100 & - & - & 97 \\
\hline
\end{tabular}




\section{Wool Carpet}

In all three experiments the wool carpet specimens burned for some distance along the corridor, but did not sustain combustion for the whole length of the corridor. The distances burnt were 3.0, 5.4 and 7.0 m. In Experiments 2 and 11, the carpet burned at around the $2 \mathrm{~m}$ mark for a minute or more, with air flowing into and smoke flowing out from the burn room. At around three and a half minutes, smoke patterns indicated a change in airflow with incoming air and outgoing smoke circulating in the corridor only. The fire on the carpets spread along the corridor to the respective endpoints, then died out abruptly. In Experiment 8, the corridor fire died down at the same time as the room fire, making this an outlying result. Table 3 records distance burnt along the corridor versus time, for flames $100 \mathrm{~mm}$ above the carpet as measured by thermocouples at $0.5 \mathrm{~m}$ intervals. The times end at a distance less than the final burnout distance quoted above since the flames were being laid back towards the burn room by the flow of incoming air.

TABLE 3. Distance of flame spread along corridor as a function of time

\begin{tabular}{|c|c|c|c|c|c|c|c|}
\hline Carpet type & Wool & Wool & Wool & Nylon & Nylon & P'prop. & P'prop. \\
\hline Exp. no. & 2 & 8 & 11 & 4 & 12 & 15 & 18 \\
\hline $\begin{array}{l}\text { Distance } \\
(\mathrm{m})\end{array}$ & & & $\begin{array}{l}\text { Time } \\
(\mathrm{s})\end{array}$ & & & & \\
\hline 0.0 & 140 & 160 & 160 & $145^{*}$ & $155^{*}$ & 145 & 135 \\
\hline 0.5 & 145 & 165 & 165 & 155 & 165 & $153 *$ & $143^{*}$ \\
\hline 1.0 & 155 & 165 & 170 & 175 & 275 & 160 & 150 \\
\hline 1.5 & 205 & 165 & $230 *$ & 190 & 190 & 170 & 158 \\
\hline 2.0 & $215^{*}$ & 170 & 230 & 205 & 205 & 180 & 165 \\
\hline 2.5 & 220 & & 240 & & & 185 & 170 \\
\hline 3.0 & 230 & & 245 & & & 190 & 175 \\
\hline 3.5 & 235 & & 250 & & & 198 & 180 \\
\hline 4.0 & 245 & & 255 & & & 205 & 185 \\
\hline 4.5 & 250 & & 260 & & & 210 & 193 \\
\hline 5.0 & & & 265 & & & 215 & 200 \\
\hline 5.5 & & & 270 & & & 223 & 205 \\
\hline 6.0 & & & 285 & & & 230 & 210 \\
\hline 6.5 & & & & & & 235 & 215 \\
\hline 7.0 & & & & & & 240 & 220 \\
\hline 7.5 & & & & & & 248 & 228 \\
\hline 8.0 & & & & & & 255 & 235 \\
\hline 8.5 & & & & & & 268 & 243 \\
\hline 9.0 & & & & & & 280 & 250 \\
\hline 9.5 & & & & & & 293 & 263 \\
\hline 10.0 & & & & & & 305 & 275 \\
\hline
\end{tabular}

* Indicates time at which the circulation pattern in the corridor no longer included flows of air into and smoke out of the fire test room (visual observation). 
The heat release rate versus time curves for these burns (Figure 2) show very similar initial peaks from the burning of the sofa and the carpet in the room, peaking at $2300-2500 \mathrm{~kW}$ after 130-160 seconds. The curve for Experiment 8 then drops away, confirming much less corridor fire involvement than for the other two experiments.

\section{Nylon Carpet}

The two specimens of nylon carpet burnt out as the room burn died down, Experiments 4 and 12 travelling 2.6 and $3.4 \mathrm{~m}$ respectively along the corridor. Table 3 gives the distance versus time figures for these experiments. They indicate a steady advance for a short distance along the corridor. The heat release rate curves in Figure 3 show a pronounced second peak related to the burning in the corridor. Comparison of Figure 3 with Figure 2 shows that for the nylon carpet (Experiments 4 and 12) and the wool-pile carpet specimen which burned a similar distance (Experiment 8), the total heat release was greater for the nylon carpet specimens.

\section{Polypropylene Carpet}

The two specimens of polypropylene carpet burnt strongly over the whole length of the corridor. Table 3 gives distance versus time data for these experiments. In both experiments, the carpet showed a steady-state rate of spread of around $5 \mathrm{~m}$ per minute. The heat release rate curves in Figure 3 show steady-state conditions from the time the room fire ceased having an effect (170-180 seconds) until the burn neared the far end of the corridor (260-280 seconds). This suggests that flame spread on this carpet in a corridor with these cross-sectional dimensions would continue, ventilation permitting, until all the carpet was burnt. Figure 4 shows the flame profile for a polypropylene carpet burning at the end of the corridor, indicating a flame leanback of more than two metres. This profile was measured from the clean-burnt areas on the corridor wall.

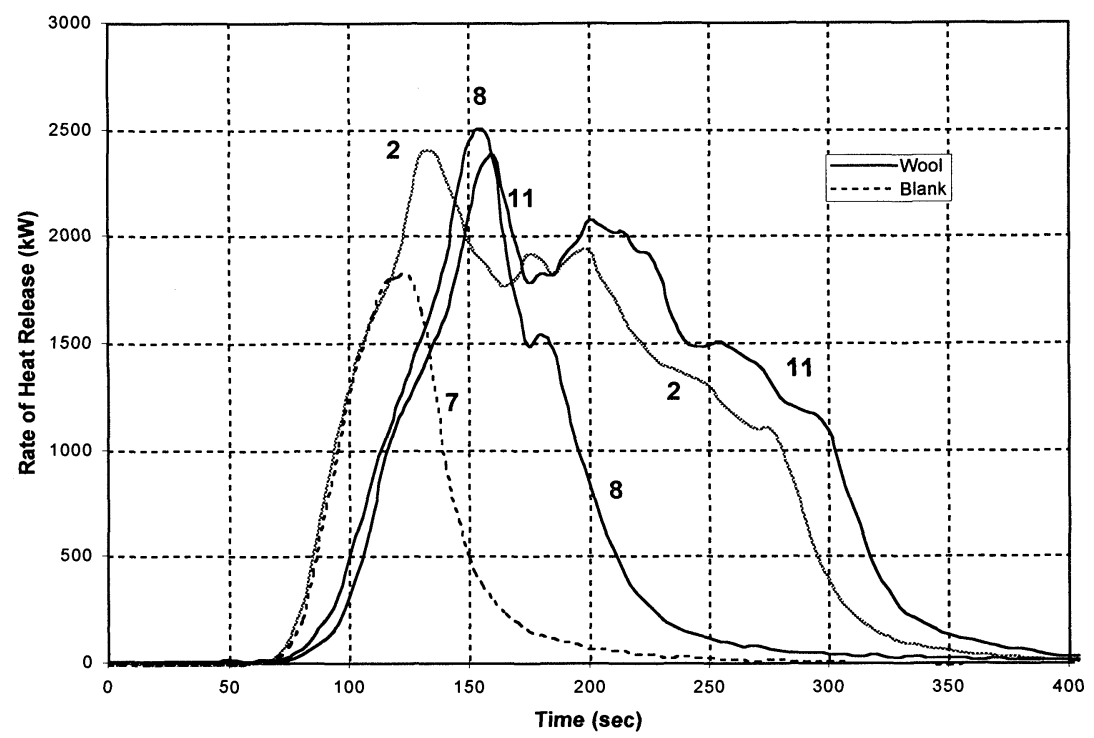

FIGURE 2. Rate of heat release versus time for wool carpet and blank burns 


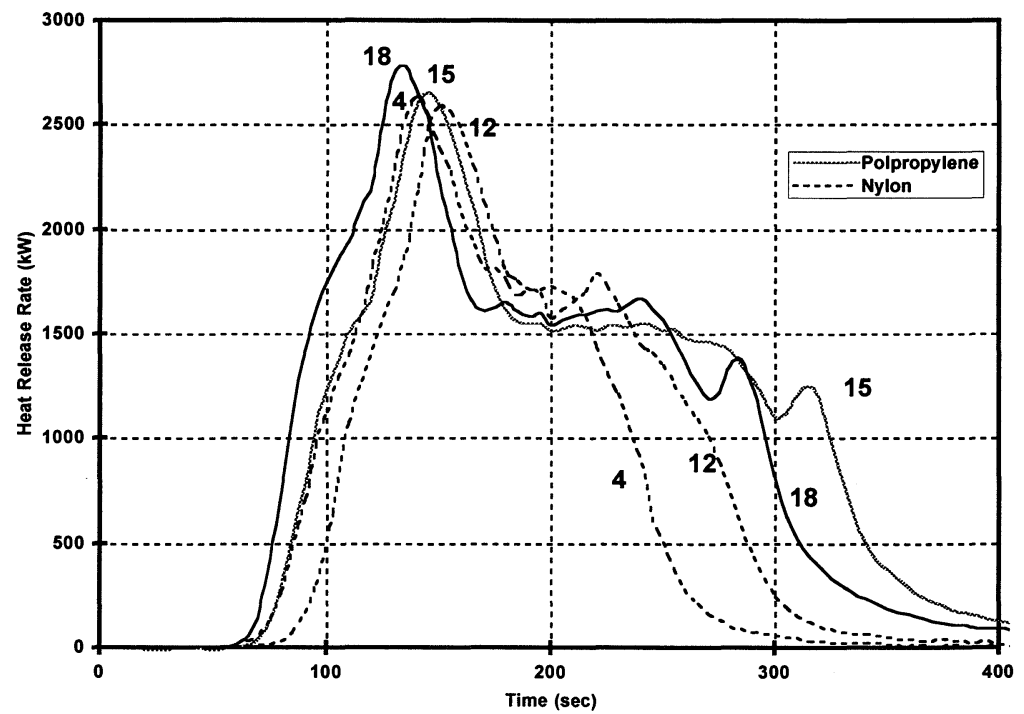

FIGURE 3. Rate of heat release versus time for nylon and polypropylene carpets

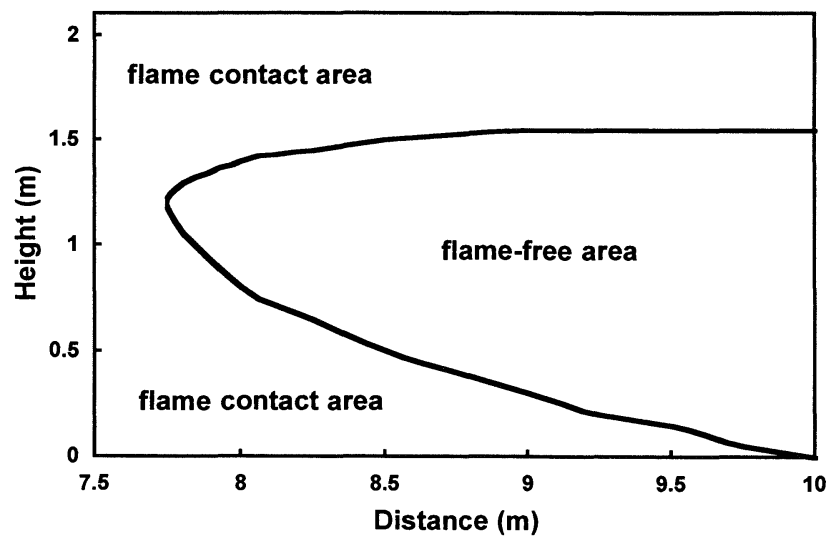

FIGURE 4. Corridor wall flame profile for polypropylene carpet burning at the end of the corridor

\section{Comparison of AS 1530 Part 3 and ASTM E648 Results}

On the basis of the AS 1530 Part 3 results (see Table 1) the poor fire behaviour of the polypropylene carpet could be predicted. Similarly, the wool carpet could be expected to perform well on the basis of its AS 1530 Part 3 results. The AS 1530 Part 3 results for the nylon carpet, however, give a completely misleading forecast of its large-scale performance. They suggest fire behaviour similar to that of the polypropylene carpet. In fact, the behaviour of the nylon carpet was similar to that of the benchmark wool carpet. 
The ASTM E648 results (see Table 1) were broadly in line with the corridor results but further testing will need to be carried out before a useful correlation can be attempted.

\section{CONCLUSION}

The fire room and corridor facility has been successfully used to examine the large-scale fire performance of carpets, and appears likely to be a useful tool for assessing the validity of small-scale fire test methods. The room and corridor facility design and materials performed up to technical expectations, and the demountability of the corridor proved to be a valuable feature in optimising the use of laboratory space.

\section{FURTHER WORK}

Further work is underway to examine a wider range of floor coverings in the corridor, to AS 1530 Part 3 and on alternative test methods, in order to determine which small-scale test method best predicts the large-scale fire performance of floor coverings. Plans are in hand to instrument the corridor with anemometer arrays and floor-mounted radiometers to allow gathering of data suited to computer modelling. A gas burner controlled by a programmed mass flow meter will be used to reproducibly simulate the burning of furniture in the fire test room.

\section{AKNOWLEDGMENTS}

The authors thank Dr Caird Ramsay (who at the time led the Fire Projects at the Division's Highett laboratories, and has since left CSIRO) for his guidance in the conduct of this work. They also thank Mr Alex Webb and Mr Justin Leonard for their valuable assistance in conducting the experiments.

\section{REFERENCES}

1. Standards Australia, Methods for Fire Tests on Building Materials, Components and Structures: Part 3 - Simultaneous Determination of Ignitability, Flame Propagation, Heat Release and Smoke Release, AS 1530.3, Standards Australia, Sydney, 1989.

2. Australian Building Codes Board, Building Code of Australia, ABCB, Canberra, 1990.

3. ASTM, Standard Test Method for Critical Radiant Flux of Floor-Covering Systems Using a Radiant Heat Energy Source, ASTM E648, American Society for Testing and Materials, Philadelphia, Pennsylvania, 1993.

4. International Organisation for Standardisation, Fire Tests - Reaction to Fire: Part 1 - Heat Release Rate from Building Products (Cone Calorimeter Method), ISO 5660.1, International Organisation for Standardisation, Geneva, 1993.

5. ASTM, Standard Test Method for Heat and Visible Smoke Release Rates for Materials and Products Using an Oxygen Consumption Calorimeter, ASTM E1354, American Society for Testing and Materials. Philadelphia, Pennsylvania, 1992.

6. Fung, F.C.W., Suchomel, M.R. and Oglesby, P.L., "The NBS Program on Corridor Fires", Fire J., 65:3, 41-48, 1973. 
7. Quintiere, J. and Huggett, C., An Evaluation of Flame Spread Test Methods for Floor Covering Materials, Special Publication 411, National Bureau of Standards, Government Printing Office, Washington, DC, pp. 59-89, November 1974.

8. Quintiere, J., A Characterization and Analysis of NBS Corridor Fire Experiments in Order to Evaluate the Behavior and Performance of Floor Covering Materials, NBSIR 75-691, National Bureau of Standards, 1975.

9. Christian, W. J. and Waterman, T. E., "Fire Behaviour of Interior Finish Materials", J. Fire Tech., 6:3, 165, 1970.

10. McGuire, J.H., "The Spread of Fire in Corridors", J. Fire Tech., 2:4, 103, 1968.

11. International Organisation for Standardisation, Fire Tests - Full Scale Room Tests for Surface Products, ISO 9705, International Organisation for Standardisation, Geneva, 1983.

12. Nordtest, Nordtest Method NT Fire 032, Nordtest, Finland, 1987.

13. Standards Australia, Flexible Cellular Polyurethane for Seat Cushioning and Bedding, AS 2281, Standards Australia, Sydney, 1993. 